\title{
Peran Komunikasi Interpersonal terhadap Kerjasama Team Mahasiswa Kkn
}

\author{
Ajeng Safitri ${ }^{1}$, Nur Fitriyana ${ }^{2}$ \\ ${ }^{1,2}$ Psikologi Islam, Fakultas Studi Islam, Universitas Muhammadiyah Riau \\ Jl. Tuanku Tambusai, Pekanbaru, Indonesia \\ ajengsafitri@umri.ac.id
}

\begin{abstract}
Abstrak
Kesalahpahaman dalam komunikasi sering terjadi antar angggota kelompok KKN UMRI yang berujung pada perselisihan sesama anggota, dan berimbas dalam penyelesaian program kerja KKN. Komunikasi interpersonal menjadi fokus dalam penelitian ini untuk melihat kontribusinya terhadap kerjasama tim pada mahasiswa KKN UMRI yang dilakukan pada saat pandemik covid-19. Sample penelitian menggunakan mahasiswa KKN UMRI tahun 2020 yang jumlah 281 orang, dengan teknik purposive sampling. Pengumpulan data menggunakan skala kerjasama tim dan skala komunikasi interpersonal yang dianalisa menggunakan Uji Korelasi Parametrik Pearson, untuk melihat hubungan antara komunikasi interpersonal dengan kerjasama tim pada mahasiswa KKN UMRI. Nilai koefisien korelasi dari hasil uji analisa korelasi antara kerjasama tim terhadap komunikasi interpersonal ialah $0,048$ dengan tingkat signifikansi ( $p) 0,418(\mathrm{p}>0,05)$ yang artinya komunikasi interpersonal tidak berkontribusi terhadap kerjasama tim pada mahasiswa KKN UMRI. Hal ini bisa dikarenakan durasi pelaksanaan KKN yang hanya 14 hari dan komunikasi antar anggota kelompok menggunakan media komunikasi online daripada tatap muka langsung, sehingga keterbukaan dan kepercayaan antar anggota kelompok sukar tercipta untuk menumbuhkan kerjasama tim. Berdasarkan temuan dalam penelitian ini, penelitian selanjutnya perlu memperhatikan aspek dalam komunikasi seperti keterbukaan dan kepercayaan, serta faktor durasi tatap muka antar anggota kelompok untuk melihat kerjasama tim pada kelompok tersebut.
\end{abstract}

Kata kunci: Kerjasama Tim; KKN UMRI; Komunikasi Interpersonal; Mahasiswa

\begin{abstract}
Misunderstandings in communication often occur between members of the KKN UMRI group which lead to disputes among members, and have an impact in the completion of the KKN work programs. Interpersonal communication became the focus of this research to see its contribution to teamwork to KKN UMRI students which was carried out during the Covid-19 pandemic. The research sample used 281 students of KKN UMRI in 2020, with a purposive sampling technique. The data collection used the scale of teamwork and the scale of interpersonal communication which were analyzed using the Pearson Parametric Correlation Test, to see the relationship between interpersonal communication and teamwork in KKN UMRI students. The correlation coefficient value of the correlation analysis test result between teamwork to interpersonal communication is 0.048 with a significance level $(p)$ of 0.418 ( $p>0.05$ ), which means that interpersonal communication does not contribute to teamwork in KKN UMRI students. This could be due to the duration of KKN implementation which is only 14 days and communication between group members uses online communication media rather than face to face, so that openness and trust between group members is difficult to create to foster teamwork. Based on the findings in this study, further research needs to pay attention to aspects of communication such as openness and trust, as well as the face-to-face duration factor between group members to see teamwork in the group.
\end{abstract}

Keywords: Teamwork; UMRI KKN; Interpersonal Communication; College student

\section{PENDAHULUAN}

Pelaksanaan KKN UMRI tahun 2020 dilakukan secara daring maupun luring dengan tetap menjalankan protocol kesehatan new normal selama empat belas hari. Konsep pengabdian 
kepada masayarakat ini disesuaikan dengan kebutuhan masyarakat Riau selama pandemik covid-19 baik di bidang ekonomi, kesehatan, pangan, dan juga pendidikan dengan memanfaatkan berbagai media sosial maupun terjun langsung kepada masyarakat di sekitar tempat tinggal mahasiswa (LPPM UMRI, 2020).

Mengelola suatu kelompok dari latar belakang keilmuan dan karakter yang berbeda membutuhkan keterampilan komunikasi untuk dapat menyatukan individu dalam melaksanakan program kerja KKN secara bersama-sama. Komunikasi diperlukan untuk menjalin hubungan saling menghargai dan saling menghormati antar individu dengan tujuan untuk mencapai keberhasilan kerja yang sesuai harapan bersama untuk kemajuan kelompok. Berdasarkan Focus Group Discussion (FGD) yang dilakukan oleh peneliti pada kelompok KKN-PPM tahun 2019, diketahui bahwa kesalahpahaman dalam komunikasi sering terjadi antar anggota kelompok KKN-PPM karena penyampaian pesan yang kurang bisa diterima oleh anggota lainnya, yang berujung pada perselisihan sesama anggota. Sekitar $40 \%$ anggota dari kelompok KKN-PPM dinilai kurang aktif dan sulit diajak kerjasama dengan anggota kelompok dalam menjalankan program kerja KKN-PPM. Temuan ini dinilai kurang mencerminkan budaya mutu UMRI yang menuntut perilaku seluruh sivitas akademika UMRI (terutama mahasiswa) untuk selalu aktif menjalankan tanggung jawab yang dibebankan kepadanya, semangat dalam usaha memajukan UMRI, dan maju secara bersama-sama untuk mencapai tujuan organisasi (LPPKM UMRI, 2017).

Timbulnya konflik akibat komunikasi yang buruk dalam kelompok bisa memunculkan stres dan terhambatnya kerja tim untuk mencapai tujuan bersama (Hutagulung, 2018). Suatu aktivitas kerja dalam pencapaian suatu tujuan yang dilakukan secara gotong royong disebut sebagai kerjasama tim (Umar, 2011). Kerjasama hanya bisa dilakukan jika semua orang di dalam kelompok memperoleh manfaat dari hasil kerja bersama. Kerjasama tidak bisa terjadi jika dalam prosesnya ada pihak yang dirugikan. Salah satu upaya untuk mewujudkan kerjasama adalah dengan menjaga komunikasi yang baik antar anggota kelompok agar memiliki satu visi untuk mencapai keberhasilan kelompok. Kurangnya komunikasi antar anggota kelompok maupun antara anggota dan ketua menjadi penyebab seringnya muncul permasalahan di dalam kelompok (Lakoy, 2015).

Komunikasi diperlukan untuk menjalin hubungan saling menghargai dan saling menghormati antar individu dengan tujuan untuk mencapai keberhasilan kerja yang sesuai harapan bersama untuk kemajuan kelompok (Bahri, 2018). Komunikasi yang dilakukan beberapa individu secara tatap muka dan dapat mengetahui langsung respon verbal maupun nonverbal dari komunikator merupakan pengertian komunikasi interpersonal (Mulyana, 2011). Komunikasi interpersonal yang baik memiliki sifat dialogis dimana dari adanya keterbukaan diri mampu memunculkan feedback dan pemahaman satu dengan lainnya (Peranginangin \& Perbawaningsih, 2017). Komunikasi yang terjalin akrab antar anggota kelompok dimulai dari membicarakan kehidupan pribadi masing-masing anggota hingga munculnya perasaan nyaman dalam hubungan interpersonal tersebut. Hubungan interpersonal yang terjalin antar sesama anggota kelompok menyebabkan adanya pertukaran pengetahuan dan keterampilan menyelesaikan tugas, bahkan muncul sikap rela membantu menyelesaikan pekerjaan bersamasama jika ada anggota lain yang mengalami kesulitan (Santoso et al., 2018). Namun, jika adanya ketidaknyaman antar anggota kelompok akan menimbulkan hubungan yang buruk antar anggota kelompok dan menghambat kemajuan organisasi, ketika komunikasi interpersonal tidak berjalan secara efektif (Bahri, 2018), dan bisa mempengaruhi kerjasama kelompok dalam menyelesaikan permasalahan (Santoso et al., 2018). Terlebih dalam pembentukkan kelompok 
KKN UMRI terdiri dari beberapa program studi dan karakter yang berbeda. Jika komunikasi interpersonal tidak berjalan dengan baik, maka bisa menimbulkan hubungan yang kurang baik antar anggota kelompok dan suasana kelompok yang kurang nyaman. Hal ini bisa berimbas pada penyelesaikan program kerja kelompok karena kurangnya kerjasama antar anggota. Berdasarkan hal tersebut, penelitian ini ingin melihat apakah komunikasi interpersonal memiliki peran dalam kerjasama kelompok pada mahasiswa yang mengikuti KKN UMRI pada tahun 2020.

\section{METODE}

Penelitian ini menggunakan metode penelitian kuantitatif dengan jumlah sampel 281 orang mahasiswa KKN UMRI tahun 2020 dengan menggunakan teknik purposive sampling. Skala kerjasama tim dan skala komunikasi interpersonal merupakan skala yang dipakai saat pengumpulan data. Aspek yang digunakan dalam skala kerjasama tim adalah interaktif, interpersonal, pemecahan masalah, dan keterampilan komunikasi dengan jumlah pernyataan sebanyak 11 aitem. Skala kerjasama tim memiliki koefisien reliabilitas $\alpha$ sebesar 0,864 dengan rentang nilai koefisien aitem $0,319 \leq \mathrm{rxy} \leq 0,677$. Skala komunikasi interpersonal terdiri dari aspek keterbukaan, sikap positif, kesetaraan, sikap suportif dan empati, dengan jumlah pernyataan sebanyak 13 aitem. Skala komunikasi interpersonal memiliki koefisien reliabilitas $\alpha$ sebesar 0,848 dengan rentang nilai koefisien aitem $0,306 \leq \mathrm{rxy} \leq 0,675$.

\section{Hasil Uji Asumsi}

\section{HASIL}

Uji asumsi yang dilakukan adalah uji normalitas dan linieritas pada variable kerjasama tim dan komunikasi interpersonal. Berdasarkan uji normalitas pada kedua variabel penelitian yang telah dilakukan, diketahui angka perolehan Skewness variabel Kerjasama Tim ialah -0,578 dengan nilai kurtosis $-0,851(-1,96 \leq \mathrm{t} \leq 1,96)$, sedangkan nilai skewness variabel komunikasi interpersonal sebesar $-0,78$ dengan nilai kurtosis sebesar 1,254 $(-1,96 \leq \mathrm{t} \leq 1,96)$. Hasil uji asumsi normalitas dari kedua variabel penelitian ini yaitu kerjasama tim dan komunikasi interpersonal menunjukkan adanya distribusi normal. Sedang berdasarkan uji asumsi linieritas kerjasama tim dan komunikasi intepersonal diketahui bahwa adanya hubungan linier di antara kedua variabel dengan $F$ sebesar 1,566 dan $p$ sebesar $0,020(p<0,05)$.

\section{Uji Hipotesis}

Uji hipotesisi dilakukan jika uji asumsi sudah terlaksana. Tujuan dari uji hipotesis ini ialah untuk melihat efektifitas komunikasi interpersonal terhadap kerjasama tim. Uji hipotesis dilakukan dengan menggunakan uji korelasi parametrik pearson. Berdasarkan analisa korelasi pearson diketahui koefisien korelasi antara variabel kerjasama tim dengan komunikasi interpersonal sebesar 0,048 dengan $\mathrm{p}$ senilai $0,418(\mathrm{p}>0,05)$. Artinya, komunikasi interpersonal tidak memiliki peran terhadap kerjasama tim pada mahasiswa KKN UMRI.

\section{DISKUSI}

Hasil uji hipotesis antara dua variabel dalam penelitian ini menunjukkan bahwa tidak ada hubungan yang signifikan antara komunikasi interpersonal dengan kerjasama tim pada mahasiswa KKN UMRI. Hal ini bisa disebabkan karena kegiatan KKN UMRI tahun 2020 
selama masa pandemi covid-19 dilakukan secara daring dan luring dalam waktu pelaksanaan 14 hari. Minimnya durasi tatap muka dalam menyelesaikan pekerja dimungkinkan mempengaruhi kerjasama antar anggota kelompok (Wulandari et al., 2015) dalam melaksanakan program kerja, terlebih koordinasi pelaksanaan program kerja lebih banyak menggunakan media komunikasi seperti grup What's App (WA). Komunikasi melalui media online mampu menimbulkan beberapa hambatan teknis seperti permasalahan sarana prasarana komunikasi, metode komunikasi, kondisi fisik, kondisi lingkungan, waktu komunikasi, dan perbedaan latar belakang sosial. Hambatan-hambatan ini bisa menyebabkan komunikasi tidak berjalan secara efektif (Muslih, 2020). Jika komunikasi dua arah terjadi secara komprehensif, maka akan muncul kepercayaan antara anggota tim yang kemudian menjadi pondasi terbangunnya kerjasama tim (Buchholz, 2011).

Anjuran pemerintah untuk melakukan social distancing ketika berinteraksi dengan orang lain pada masa new normal berdampak pada peningkatan penggunaan media sosial dalam berhubungan dengan orang lain. Penggunaan media sosial ini mempengaruhi kepercayaan seseorang dalam berkomunikasi yang terpisah oleh jarak. Adanya jarak geografis dan budaya antara individu mempengaruhi munculnya kerentanan dalam mempercayai seseorang. Individu yang belum memiliki kepercayaan terhadap orang lain akan sukar untuk memulai kerjasama (Rahmawati \& Afrizal, 2020). KKN UMRI tahun 2020 dilakukan pada masa pandemic covid19 yang mengharuskan setiap mahasiswa yang tergabung dalam satu kelompok KKN lebih banyak berkomunikasi melalui media komunikasi group What's App (WA), dan dimana sebagian besar anggota kelompok belum pernah mengenal satu sama lain karena berasal dari program studi berbeda. Adanya jarak antar anggota kelompok dalam berkomunikasi secara online dinilai kurang efektif untuk menumbuhkan rasa saling percaya dan terbuka antar sesama anggota kelompok KKN UMRI.

Komunikasi menggunakan media online cenderung menyebabkan seseorang menjadi individualis. Individu dalam budaya individualis lebih fokus memiliki tujuan pribadi daripada tujuan kelompok, dan berperilaku sesuai dengan sikap masing-masing daripada norma dalam masyarakat (Hofstede, 2011). Perilaku ini muncul disebabkan kondisi pandemi yang terjadi saat ini, dimana individu lebih mempersiapkan diri dalam menjaga diri sendiri dan orang-orang terdekatnya dari bahaya pandemi.

Ketidakmampuan menjalin komunikasi tatap muka yang intens karena kondisi pandemi covid-19, menjadi salah satu hambatan bagi anggota kelompok dalam berdiskusi dan membangun kerjasama. Hal ini sesuai dengan pendapat Setiyanti (2012), bahwa kesamaan tempat dalam berkomunikasi bisa menjadi dasar bagi terwujudnya kerja sama karena akan memudahkan seluruh anggota kelompok atau organisasi untuk saling berkomunikasi, berdiskusi atau berargumentasi.

Menurut penelitian yang dilakukan Santoso et al (2018), kerjasama terbangun antar anggota kelompok jika mampu bertemu setiap hari atau 5 hari seminggu selama 6 jam. Mahasiswa KKN UMRI tahun 2020 tidak disarankan untuk bertemu atau berkumpul setiap hari, dan disarankan melakukan koordinasi secara online untuk menghindari kerumuman. Pelaksanaan program kelompok pun disarankan minimal 1 kali seminggu terjun ke masyarakat untuk merealisasikan program kelompok sesuia dengan kebutuhan masyarakat di daerah tempat tinggal mahasiswa $\mathrm{KKN}$, dengan tetap mematuhi protokol kesehatan new normal yaitu memakai masker, mencuci tangan, menjaga jarak dengan batas maksimal 15 orang dalam setiap kegiatan KKN. Meskipun memiliki inkonsitensi dengan temuan penelitian sebelumnya, hasil penelitian ini dapat menjadi masukan bagi penelitian selanjutnya. 


\section{KESIMPULAN}

Hasil penelitian ini menunjukkan pelaksanaan KKN UMRI tahun 2020 yang dilakukan secara daring dan luring berkaitan dengan komunikasi interpersonal tidak berjalan secara efektif dan tidak mempengaruhi kerjasama tim. Hal ini karena durasi pelaksanaan KKN yang hanya 14 hari, dan komunikasi antar anggota kelompok lebih banyak dilakukan secara daring menggunakan media komunikasi What's App (WA) dibandingkan tatap muka langsung. Keterbukaan dan kepercayaan antar anggota kelompok sukar tercipta karena faktor komunikasi jarak jauh menggunakan media komunikasi dan belum saling mengenalnya antar anggota kelompok karena tidak bertemu setiap hari seperti KKN pada tahun-tahun sebelumnya. Penelitian selanjutnya perlu memperhatikan aspek dalam komunikasi seperti keterbukaan dan kepercayaan, serta faktor durasi tatap muka antar anggota kelompok untuk melihat kerjasama tim pada kelompok tersebut.

\section{UCAPAN TERIMA KASIH}

Terima kasih penulis hanturkan kepada Kementrian Riset dan Teknologi/ Badan Riset dan Inovasi Nasional Republik Indonesia (Ristek-Brin) atas dukungan materi yang diberikan. Terima kasih Penulis juga hanturkan kepada Universitas Muhammadiyah Riau (UMRI) yang selalu memberi motivasi untuk melakukan penelitian sebagai salah satu kewajiban dosen dalam Catur Dharma. Penulis juga menghaturkan terima kasih kepada Mahasiswa KKN UMRI yang sudah bersedia membantu penulis dalam proses pengumpulan data penelitian. Tidak luput pula terima kasih dihanturkan kepada tim mahasiswa dan tim dosen peneliti Psikologi Islam UMRI atas kerjasamanya dalam menyelesaikan penelitian ini.

\section{DAFTAR PUSTAKA}

Bahri, A. N. (2018). Peran Komunikasi Antar Pribadi Pada Lingkungan Kerja Dalam Perspektif Islam. Jurnal Ilmiah Sosiologi Agama (Jisa), 1(1), 128-142.

Buchholz, L. (2011). Effective Leadership. Plastic Surgical Nursing, 31(2), 87.

Hofstede, G. (2011). Dimensionalizing Cultures: The Hofstede Model in Context. Online Readings in Psychology and Culture, 2(1), 1-26.

Hutagulung, I. (2018). Peran Komunikasi Antar Pribadi Pada Konflik Organisasi. Jurnal Bakti Masyarakat Indonesia, 1(1), 243-249.

Lakoy, A. C. (2015). Pengaruh Komunikasi, Kerjasama Kelompok, dan Kreativitas terhadap Kinerja Karyawan pada Hotel Aryaduta Manado. Jurnal EMBA, 3(3), 981-991.

Mulyana, D. (2011). Ilmu Komunikasi: Suatu Pengantar. Remaja Rosdakarya.

Muslih, B. (2020). Urgensi Komunikasi dalam Menumbuhkan Motivasi di Era Pandemi Covid19. Jurnal Penelitian Manajemen Terapan (PENATARAN), 5(1), 57-65.

Peranginangin, B. B., \& Perbawaningsih, Y. (2017). Model Komunikasi Interpersonal Generasi Muda Suku Batak Karo di Yogyakarta Melalui Tradisi Ertutur. Jurnal ASPIKOM, 2(6), 425.

Rahmawati, R., \& Afrizal, S. (2020). Cognitive Based Trust and Afective Based Trust dalam Membangun Komunikasi Interpersonal Melalui Penggunaan Jejaring Sosial dimasa Pandemi Covid-19. Jurnal Hermeneutika, 6(1).

Santoso, M. B., Rachim, H. A., \& Syauqina, D. A. (2018). Komunikasi Kelompok Sebagai Faktor Pendorong Terbentuknya Kerjasama Dalam Menyelesaikan Pekerjaan K3L Di 
Lingkungan Universitas Padjadjaran. Prosiding Penelitian Dan Pengabdian Kepada Masyarakat, 5(2), 198.

Setiyanti, S. W. (2012). Membangun Kerja Sama Tim (Kelompok). Jurnal STIE Semarang, $4(3), 59-65$.

Umar, T. (2011). Pengaruh Outbound Training Terhadap Peningkatan Rasa Percaya Diri Kepemimpinan dan Kerjasama Tim. Jurnal Ilmiah Spirit, 11(3), 59-69.

LPPKM UMRI. (2017). Sistem Penjaminan Mutu Internal. In Universitas Muhammadiyah Riau.

LPPM UMRI. (2020). Panduan Pelaksanaan “KKN Merdeka” Tahun 2020. LPPM UMRI.

Wulandari, B., Arifin, F., \& Irmawati, D. (2015). Peningkatan Kemampuan Kerjasama dalam Tim Melalui Pembelajaran Berbasis Lesson Study. Jurnal Electronics, Informatics, and Vocational Education (ELINVO), 1(1), 9-16. 